\title{
Algunas puntualizaciones sobre el fragmento de Valter y Griselda del Ms. 89 de la Universidad de Barcelona
}

\author{
Roxana Recio \\ Creighton University
}

Per a en Josep, amb afecte.

Josep Ysern publicó hace unos años un artículo titulado "Sobre el fragment del Valter e Griselda contingut en el Ms. 89 pertanyent a la Biblioteca de la Universitat de Barcelona". Se trata de un estudio fundamental para la tradición de la obra Valter y Griselda que, como se sabe, aparece en Boccaccio en el que se lleva a cabo un estudio comparativo entre este fragmento y las traducciones del texto editado y más conocido de Bernat Metge, la versión latina de Petrarca y, por supuesto, lo compara con el texto de Boccaccio. En su análisis, Ysern señala puntos decisivos para el estudio de estos textos.

Sin embargo, en el trabajo que ahora presento, quiero ahondar en las prácticas traductológicas y narrativas tanto de Petrarca como de Metge, contando siempre con el original, con Boccaccio. A través de un análisis textual, en ocasiones, de las obras utilizadas por Ysern, nos centraremos en el modo en que este fragmento se ha traducido, por qué aparece en una recopilación de exempla y en qué consiste su valor en relación a la época. Mis derroteros van por el campo de la tradición de la traducción y, desde luego, hago mención a algunas traducciones castellanas ${ }^{1}$.

\footnotetext{
${ }^{1}$ Para un panorama más amplio de las traducciones castellanas, véanse Juan Carlos Conde, "Un aspecto de la recepción del Decamerón en la Península Ibérica, a la sombra de Petrarca: La historia
} 
Como se sabe, esta historia pertenece a la Jornada Diez del Decamerón de Boccaccio, concretamente la novela última antes de las "conclusiones del autor", y fue tan del gusto de Petrarca que la tradujo al latín ${ }^{2}$. Esta historia, estupendamente resumida por Ysern ${ }^{3}$,lleva al límite la sumisión de una mujer hacia su esposo $^{4}$. Lo que Boccaccio hace en esta historia es un cambio muy importante: consigue que una problemática de carácter moral del tipo exempla se transforme en materia narrativa distinta: la novelesca. Es muy interesante que la novela termine con una canción de Fiammetta que habla sobre la inutilidad de los celos. Cuando digo "novelesca", me refiero a que la historia presenta unas características muy flexibles para la amplificación de ciertas cuestiones y pasajes, para los diálogos y para la ideología de la propia historia que se cuenta. Me refiero, en definitiva, a la nueva concepción que Boccaccio trae a Europa ${ }^{5}$.

La Jornada Décima no presenta al lector en sus historias un tema único, sino que en esa Jornada las novelas tratan de distintos temas y con final feliz. En ella, se "ragiona di chi liberalmente ovvero magnificamente alcuna cosa operasse intorno a' fatti d'amore o d'altra cosa". Cavallini explica muy bien la temática de las novelas de la Jornada ${ }^{7}$. SegúnGuido Almansi, son historias que se cuentan dentro de un marco narrativo, típico en el Decamerón:

de Griselda", Cuadernos de Filología Italiana, 8 (2001), pp. 351-371, y Juan Carlos Conde y Víctor Infantes, La historia de Griseldis (c. 1554), Baroni, Viareggio-Luca, 2000.

${ }^{2}$ Roxana Recio, "Petrarca traductor: los cambios de traducción peninsular a través de la historia de Valter y Griselda", Ensayos sobre la traducción medieval (Homenaje a Margherita Morreale), eds. Roxana Recio y Tomás Martínez Romero, Universitat Jaume I, Castellón, 2001, pp. 291-308.

${ }^{3}$ Josep Antoni Ysern i Lagarda, "Sobre el fragment de Walter e Griselda contingut en el ms. 89 pertanyent a la Biblioteca de la Universitat de Barcelona", Revista de Filologia Romànica, 17(2000), pp. 342-343.

${ }^{4}$ Giovanni Boccaccio, Decameron, ed. Cesare Segre, Mursia, Milano, 1966. Las citas son de esta edición.

${ }^{5}$ Explico parte de estas cuestiones en mi trabajo a punto de salir, "Cuando hay pleito descubierto: ecos del quehacer narrativo de Boccaccio en el Juez de los divorcios de Cervantes", y también en mi trabajo "Autor y lector en la traducción catalana del Decamerón de Boccaccio: análisis de una asimilación”, Scripta, 1 (2013), pp. 283-309.

${ }^{6}$ Decameron, p. 593.

${ }^{7}$ Giorgio Cavallini, La decima giornata del Decameron, Bulzoni, Roma, 1980, pp. 15-16. 
The cornice [marco narrativo] also acts as a subtle lever, gradually transferring the complex material of the stories towards a model of ascent, commencing with the scandalous turpitude of Ciappelletto and progressing through to the apparently sublime humility of Griselda, going by way of the worldly promptings of human intelligence and exploiting the interventions of change and virtue. It is an ideal model which is hinted at but not exemplified in the Decameron, since among the many other levels at which the author plays with the reader's reactions, he is content to allow a glimmer of this ascent to come through to them, while at the same time severely curtailing the triumph of virtue and goodness by a number of doubtful examples of saintly behaviour in the Tenth Day itself. The cornice manages to insert even the most fantastic stories into a recognizable human dimension, so that patina of almost domestic familiarity is allowed to tone down the purest flights of imagination ${ }^{8}$.

Boccaccio crea un mundo en el que esas historias, apelando a la imaginación, son muy creíbles. Incluso puede incluirse el caso de la sumisión de Griselda. La canción al final puesta en boca de Fiammetta responde a ese final feliz de la Jorna$\mathrm{da}^{9}$. Sin embargo, para Almansi, lo que vemos en esa Jornada a través de las Diez novelas es un proceso de escritura bastante problemático.

Según Almansi, estas novelas de la Jornada Décima, tienen una finalidad estructural concreta en donde se ve que el narrador es consciente de la dificultad que supone contar una historia:

This awareness intrudes not just at the primary aesthetic level, in the sense in which every work of art exalts itself and the artifices it uses, but also at a structural level, since this is a case where we have to pay special attention to the technique of story-telling.

\footnotetext{
${ }^{8}$ Guido Almansi, The Writer as Liar: Narrative Technique in the Decameron, Routledge-Kegan Paul, Londres-Boston, 1975, p. 13. El subrayado es nuestro.

${ }^{9}$ Trato las canciones del Decamerón, en mi trabajo "Música y canciones en Boccaccio: la nueva narrativa europea", eds. Isabel Colón, David Caro Bragado et ál., Los viajes de Pampinea: novella y novela española en los Siglos de Oro, Sial, Madrid, 2013, pp. 29-44.
} 
This latter is presented to us in a double guise: not only do we have the stories themselves, which vary in their deployment of narrative skills, but we also have the courtly contest which the story-tellers fight in an atmosphere of idyll and good taste in order to entertain and compete with the rest of the company. This means that it would certainly be an oversimplification of the Tenth Day to treat it simply as a progressive ascent towards virtue. We should also look at the decisive parallel ascent towards narrative inventiveness, in other words the creative process involved in attempting to invent ever more convincing examples of human magnanimity and virtue. And this is valid both for the author and for the narrators ${ }^{10}$.

Es precisamente esa dificultad, desde luego superada por Boccaccio, la que convierte su narrativa en única y la que nos hace entender cómo una historia que tiene una carga moralizante que puede ser muy determinante, llega a ser una historia más de "entretenimiento", la idea central del Decamerón. Las canciones intercaladas son básicas para afirmar este punto en concreto. No cabe duda, por ejemplo, que en la Novela Sexta de la Jornada Diez es la canción la que sirve para dar relevancia a la connotación irrespetuosa que se busca, y no únicamente a la historia de Meuccio, Tingoccio y Mita ${ }^{11}$. La historia, tal y como aparece, antes de entrar descalzos en el agua, antes de la cena, solamente dejaría a Boccaccio como otro autor más de los que siguen los exempla, o que cuenta historias bien hiladas y narradas, con tonos más o menos picantes, tratando un tema clásico como es el del viejo que se enamora de una joven y hace el ridículo, pero nada más. No obstante, Boccaccio da un paso adelante y transforma lo meramente moral en una nueva literatura: la que admite más diálogo, más juegos ideológicos e estilísticos, la que trae en definitiva un movimiento llamado Humanismo. Con Boccaccio el exemplum pasa a ser entretenimiento literario sin connotación ideológica, de lo que dan muestra las canciones:

io non intendo deviare da' miei passati; ma, sì come essi hanno fatto, così intendo che per lo mio comandamento si canti una canzone; e per ciò che io son certa che talisono le tue can-

\footnotetext{
${ }^{10}$ Almansi, pp. 10-11.

${ }^{11}$ Decameron, pp. 616-622.
} 
zoni chentisono le tue novelle, acciò che più giorni che questo non sieno turbati da'tuoi infotuni, vogliamo che una ne dichi qual più ti piace" $(318)^{12}$.

Normalmente, resumiendo o sintetizando las distintas ideas de la novela de la Jornada, la canción aparece como el elemento esencial para poder poner un punto final intrascendente. En cambio en el Filocolo, cuando se cuenta la historia de Tanaquilla y el niño ${ }^{13}$, es curioso que, en la traducción castellana del XVI, el poema o canción que forma parte de la narración, no se independiza de la misma como en el original:

El qual se encerró en mi ánima para mirar lo que mi pensamiento hazía y, sintiendo insufientes mis ojos de mirar tan gran cosa, saliose con un lustro muy claro y púsose dentro de vuestros ojos, y en ellos por muy gran rato hizo maravillas adornándolos de nueva claridad. Y después salió con toda esta luz dexando en ellos su rastro y vi que luego se puso sobre una corona, y encima de ella junto con su resplandor me parecía a la que Tanaquilla vido [se refiere a la luz que vió Tanaquilla sobre Tulio, según cuenta la leyenda] en sueños sobre Tulio offilio pequeño garçón, y alrededor de ella andava saltando de rama en rama como paxarico que cantando dulcemente sisita muchas fojas y moviendo vuestros cabellos or diversas vezes se escondía entre ellos y otras se salía muy alegre, y parescíame muy apazible. Vile también con muy suave cantando estas palabras: yo soy el tercer cielo, cosa gentil, tan enamorado de los ojos de ésta que, si yo fuesse mortal, me moriria. Ando de hoja en hoja por mi pasatiempo cercando alrededor sus muy ruvios cabellos, encendiéndome a mí mismo en el fuego. $\mathrm{E}$ con efecto muestro la fuerça de mis biuas frechas hiriendo a qualquier que se atreva a mirar los ojos de ésta, do yo deciendo

\footnotetext{
${ }^{12}$ Véase Recio, "Música y canciones...", p. 44.

${ }^{13}$ Giovanni Boccaccio, Decameron, Filocolo, Ameto, Fiammetta, eds. Enrico Bianchi, Carlo Salinari y Natalino Sapegno, Ricciardi, Milano-Napoli, 1952, p. 870.
} 
cada hora que le plaze a ella que es señora y verdadera reyna de mis reynos. Con estas palabras dezía otras muchas ${ }^{14}$.

El hecho de que en el siglo XVI una traducción castellana incluyera dentro del marco narrativo la canción resumida dentro del mismo, demuestra que Boccaccio era percibido como un narrador por excelencia ${ }^{15}$. Lo que se intenta señalar es que la narrativa de Boccaccio había desbancado a los exempla y que ya eran obsoletos $\mathrm{y}$ aburridos para un lector que quería distraerse sin preocupaciones.

Si ahora entramos de lleno en el fragmento estudiado por Ysern, vemos, entre otras cosas, su magnífico cotejo con Boccaccio y Petrarca. Ysern llega a afirmar lo siguiente, que luego repite al final de su artículo:

No deixa de ser un contrast interessant que la mateixa narració que, en la versió de Metge, marca l'arribada d'un nou temps a la nostra literatura - independentment de l'etiqueta que emprem per a denominar-lo - aparegui també tot acompanyant una obra tan profundament medieval com ara l'exemplari contingut en el ms. 89 de la BUB (=Recull). Senyal, doncs, que alguna concomitància hom hi degué veure ${ }^{16}$.

El hecho de que la obra que nos presenta Ysern aparezca en una recopilación de exempla es muy importante. Curiosamente, Ysern habla de "l'arribada d'un nou temps", incluso cuando la obra analizada aparece en una recopilación de exempla. Tal es la manera de escribir de Metge, que permite que se haga tal juicio de valor. No creo que pueda mejorarse el cotejo hecho por Ysern en su artículo, pero lo importante es lo que nos está señalando. Si nos fijamos en el mismo fragmento, encontramos los contrastes que Ysern ya apunta, como el que veremos a

\footnotetext{
${ }^{14}$ Giovanni Boccaccio, Laberinto de amor que hizo en toscano el famoso Juan Bocacio agora nueuamente traduzido en nuestra lengua castellana, Andrés de Burgos, Sevilla, 1546, fol. cv .

${ }^{15}$ Para las cuestiones de esta traducción del capítulo cuarto del Filocolo, véase Recio, "Boccaccio y la difusión del humanismo italiano en Castilla: la traducción llamada Laberinto de Amor", ed. María Hernández Esteban, La recepción de Boccaccio en España: Actas del Seminario Internacional Complutense 18-20 de octubre de 2000, Cuadernos de Filología Italiana, Madrid, 2001, pp. 275-294, y también "Las traducciones inglesa y castellana de las Trece cuestiones de Amor de Boccaccio", Hermeneus, 5 (2003), pp. 215-233.
}

${ }^{16}$ Ysern, pp. 346 y 363. 
continuación. Primero transcribimos el fragmento y luego la versión publicada por Martín de Riquer. En el fragmento se lee lo siguiente:

Con Galter, guardant l'alegria de aquesta qui parlava e considerant la constància de la fembra ten fortment offesa, mogut de merçè no podent més sofferir dix: "Griselda mia, assats és provada a mi e coneguda la fe tua, ni.m pens dejús lo cel sie qui ten grans speriments dámor de muller hage hüts con jo!". E, aço dient, emsemps, la sua cara muller, d'alegre color per e altre no n'he haüd ni hauré; e aquesta que tu creÿes que fos sposa mia, ffilla tua és; e aquest, que creÿes que fos cunyat meu, ffill teu és: ensemps as cobrat [ço]que en diverses temps te pensaves haver perdut; sàpien aquels qui han creegut lo contrari [que] jo no son cruel [per] haver dampnada ma muller, mas, con a curiós, la he volguda provar e mos ffills he volguts amagar e no matar. Aquestas paraulaes veent aquella, per sobre de gog quax deffallent e de sobre de pietat quax fora de seyn, ab làgremes lexe's anar en abraçar de sos inffants, e en desar $\mathrm{e} \cdot \mathrm{n}$ piadors plant, tots los banyà ${ }^{17}$.

En la edición de Martín de Riquer, lo leemos de esta manera:

E Valter esgordant la alegria e constància de Griselda, la qual tantes vegades cruelment havía offesa sens rahó, havent pietat de la indigna fortuna que li havia feta sofferir,n'o pugué pus sostenir, e dix:

- O Griselda! Assats és coneguda a mi e sprovada la tua amor e feeltat, e no'm pens que dejús lo cel sia algú qui tan grans experièncias hage hagudes de amor conjugal.

E dient aquestas paraulas, fort alegrament e ab gran cupiditat abrassà la sua cara muller, la qual per la novitat de aquest fet,

${ }^{17}$ Josep-Antoni Ysern Lagarda ed., Arnau de Lieja, Recull d'exemples i miracles ordenat per alfabet, Barcino, Barcelona, 2004, vol. II, pp. 300-301. 
stava vergonyosa e axí com si fos levada de dormir e hagués spmiat alguna cosa desplasent. E dix-li:

-Tu és solament ma muller. Altra no·n he haguda n·en hauré. Sàpias que aquesta que tu pensas que sia mon cunyat és ton fill. Ara has cobrat ensemps totas les cosas que $\mathrm{n}$ diverses partidas cuydaves haver perdudas. Jo vull que sàpien tots aquells qui creen lo contrariu, que yo no·t són stat inpiadós ne cruel,ne·t he volgut matar mos fills, mas amagar aquells.

E Griselda, oynt aquestas paraulas, de gran goig tornà mig morta, e per sobres de pietat exí quax fora de son seny; e ab alegras làgremas lexà's anar sobra sos fills, e abrassant aquells e fatigant-los ab besaments spessos, bayave'ls lurs cares ab piadosos gemegaments e suspirs ${ }^{18}$.

En el cotejo minucioso de Ysern este pasaje se encuentra transcrito en las páginas $352-358^{19}$. Se señalan las partes más relevantes para las diferencias con la edición publicada, teniendo en cuenta además a Petrarca. El análisis tanto lingüístico, como de figuras retóricas o elementos añadidos, se ciñe perfectamente a un estudio detallado que consigue llamar la atención sobre este fragmento de Metge. No obstante, es en relación a la historia de la traducción en la Península donde radica su valor trascendente, ya que implica a su vez una concepción sobre el texto narrado.

La idea de que Metge no conocía la historia de Valter y Griselda de Boccaccio no es en absoluto aceptable ${ }^{20}$. La verdad es que, si eso fuera verdad, no se concibe un fragmento así, ni la elaboración posterior del texto más conocido, el que presenta Martín de Riquer. La importancia de Metge no está en su autonomía literaria, lo que estaría totalmente alejado de la metodología creativa en la época, sino en su conocimiento del mundo intelectual de aquel momento. Mencionar a Petrarca y

\footnotetext{
${ }^{18}$ Martín de Riquer, Obras de Bernat Metge, Universidad de Barcelona, Barcelona, 1959, p. 150.

${ }^{19}$ No se puede pasar por alto el cotejo que hace Butinyà en su libro de imprescindible lectura, En los orígenes del Humanismo: Bernat Metge, Universidad Nacional de educación a Distancia, Madrid, 2002, pp. 468-476.

${ }^{20}$ Giovanni Boccaccio, Decamerón, ed. Jaume Massó i Torrents, Hispanic Society of America, Nueva York, 1910, p. 610.
} 
a Boccaccio en el caso de este escritor catalán que traduce del italiano es obligado y se necesita imperiosamente una explicación de su quehacer como traductor. Sin embargo, cuando leemos este fragmento, la dimensión literaria se agranda. No se trata ya solamente de añadidos y de pertenencias, sino también de una elaboración que va de la traducción a la recreación, pero a través de un proceso intelectual consciente, difícil de encontrar en la Península en fechas tan tempranas.

Si nos fijamos bien en el pasaje transcrito por Riquer y cotejado por Ysern y Butinyà, hay algo primordial que salta a la vista: la connotación sentimental. Pueden parecer incluso exageradas tanto las palabras de Valter hacia su esposa, como la misma actitud de la esposa: su cara pálida, parece muerta y cambia de repente al escuchar las palabras del marido. También son destacables los besos y carantoñas dadas a los hijos, que según el narrador, llega a cansar "e ab alegras làgremas lexà's anar sobra sos fills, e abrassant aquells e fatigant-los ab besaments spessos, bayave'ls lurs cares ab piadosos gemegaments e suspirs". Son reacciones aparatosas pero que sirven a la idea de mover al lector, de llevarlo por una senda. No aparece así en el fragmento en el que leemos: "Aquestas paraules veent aquella, per sobre de gog quax deffallent e de sobre de pietat quax fora de seyn, $\mathrm{ab}$ làgremes lexe's anar en abraçar de sos inffants, e en desar e·n piadors plant, tots los banyà". En el fragmento todo parece muy controlado dentro de lo que es la historia: una mujer más que probada por el marido llegando a extremos, para nuestra mentalidad actual, ridículos. Martín de Riquer explica nuestra reacción de hoy en día pero en función del arte de Metge:

La lectura del Valter y Griselda puede suscitar en nosotros cierta sonrisa conmiserativa y la obra puede parecernos un ingenuo cuento que desorbita la realidad para concluir con una manida moraleja. Éste sería el resultado de una lectura que sólo atendiera al asunto y a la finalidad moral de la obra. En cuanto nos internamos en ella advertimos algo muy importante y decisivo: la maravillosa perfección de su prosa. Bernat Metge ha logrado calcar del original latino una serie de recursos estilísticos que dan al catalán un empaque solemne, sabiamente matizado con elegantes trasposiciones y armonizado 
con cadencias $^{21}$. El buen gusto del escritor ${ }^{22}$ [saber hacer según su época, decimos nosotros] le ha guiado siempre, de suerte que lo afiligranado no se ha convertido en pedante (como les ocurrirá a tantos imitadores en vulgar de la prosa latina en el $\mathrm{XV})$ ni lo artificioso en artificial. Basta comparar la prosa del Valter e Griselda con la de otros libros catalanes de la época, incluso de tanto valor literario como puede ser la Crónica de Pedro el Ceremonioso, para darse cuenta de que esta traducción de Bernat Metge supone algo importante: la instauración de una prosa artística de cuño nuevo ${ }^{23}$, que intenta reproducir en la lengua romance unos primores estilísticos que sólo parecían propios del latín clásico. Porque era clásico, a su vez, el latín de Petrarca, pero se debía a la pluma de un autor muy moderno, que hacía catorce años que había muerto y que precisamente había compuesto la historia de Griselda poco antes de morir ${ }^{24}$.

Martín de Riquer sabe perfectamente que se encuentra delante de un escritor que es consciente de cuándo el latín debe reverenciarse y cuándo, sin faltar a su cultura y a su lengua romance, debe modificarse. Lo que sucede es que, en el caso de Metge, esa modificación está tan bien llevada a cabo que no rompe con su fidelidad al latín ni a la belleza, entendiendo como belleza lo que más tarde explica Alfonso de Madrigal el Tostado y antes ya había puntualizado Cicerón: el trabajo bien hecho siguiendo unas reglas ${ }^{25}$. Para hacer lo que Metge hace hay que ser un maestro y tener una concepción asimilada del Humanismo.

${ }^{21}$ Ysern, "Sobre el fragment...”, pp. 361-363.

${ }^{22}$ Saber hacer según su época, decimos nosotros.

${ }^{23}$ Lo que Ysern llama "l'arribada d'un nou temps" (“Sobre el fragment...” p. 346).

${ }^{24}$ Riquer, pp. 48-49.

${ }^{25}$ Para la belleza y lo que aquí se trata, véase Recio, "El concepto de belleza de Alfonso de Madrigal, El Tostado: la problemática de la traducción literal y libre”, La traducción en España (siglos XIV$X V I)$, ed. Roxana Recio, Universidad de León, León, 1995, pp. 59-68, y también "La propiedad del lenguaje: poeta y poesía según Alfonso de Madrigal, el Tostado", La Corónica, 33, vol. 1 (Otoño 2004), pp. 145-162. 
Siguiendo con el texto del fragmento, no se habla de que los hijos sientan fastidio (solamente se dice que baña a sus hijos con sus lágrimas) ${ }^{26}$, ni se presenta un diálogo de una manera tan llamativa para el lector. Es, por el contrario, en Boccaccio donde la hija queda "estupefacta" 27 , adjetivo utilizado por Petrarca ${ }^{28}$, pero sin expresar ese fastidio que se aprecia en la versión que publica Martín de Riquer, la que tomamos como definitiva. Empezamos a ver cuestiones importantes: la importancia del lector, la recreación en función de algo que todavía no vemos muy claro y un proceso literario que, indiscutiblemente es traductológico, pero que también responde a una concepción de la estructura e ideología de un relato. Entramos en mundo del XIV y del XV desde el punto de vista de la creación ${ }^{29}$.

Recordemos que en Boccaccio la historia de Valter y Griselda no es más que un entretenimiento para quienes escuchan, y finalmente canta Fiammetta su canción. En una carta a Boccaccio Petrarca le dice que la tradujo al latín porque la historia le gustó, pero recuérdese que Petrarca no admite la ideología del Decamerón en general ya que la considera pestilente, nociva y poco cristiana, y la traduce entonces por su belleza y porque es la única que ensalza la fidelidad aunque esté llevada a extremos excesivos:

Quid ergo? Excucurri eum, et festini viatoris in morem, hinc atque hinc circumspiciens, nec subsistens. Animadverti alicubi librum ipsum canum dentibus lacessitum, tuo tamen baculo egregie tuaque voce defensum. Nec miratus sum. Nam et vires ingenij tui novi, et scio expertus esse hominum genus et insolens et ignavum, qui, quidquid ipsi vel nolunt vel nesciunt vel non possunt, in alijs reprehendunt, ad hoc unum docti et arguti, sed elingues ad reliqua. Delectatus sum ipso in transitu; et si

\footnotetext{
${ }^{26}$ Ysern, Recull... vol. II, p. 300 y en "Sobre el fragment...", p. 356.

${ }^{27}$ Decameron, p. 668.

${ }^{28}$ Para seguir el texto de Petrarca, puede consultarse Francesco Petrarca, Lettere Senili, ed. Giuseppe Fracassetti, Le Monnier, Florencia, 1870, vol. I, pp. 541-566), y también Jonathan Burke Severs, The Literary Relationships of Chaucer's "Clerkes Tale”, Yale University Press, New Haven, 1942, pp. 254-292.

${ }^{29}$ Debe consultarse también al respecto de la narrativa Joan Miquel Ribera Llopis, "Lectura narratológica del Valter e Griselda de Bernat Metge", Juan Paredes y Paloma. Gracia, eds., Tipología de las formas narrativas breves románicas medievales, Universidad de Granada Granada, 1998, pp. 185-207. Nuestra aproximación es diferente, pero no debe dejarse este artículo de lado.
} 
quid lascivie liberioris occurreret, excusabat etas tunc tua dum id scribers, stilus, ydioma, ipsa quoque rerum levitas et eorum qui lecturi talia videbantur (290).

Resulta muy significativo que, aunque está escrito en vulgar y lleno de lascivia, lo más importante es para Petrarca el estilo de Boccaccio. Para Petrarca se trata de un libro que se puede excusar, debido a la temprana edad del escritor. Lo verdaderamente trascendente es que confiesa que le agrada. Deja en claro que aprecia el modo en que se presenta al lector. Está bien escrito. La carta — este prefacio es en realidad la carta; el resto es la historia de Válter y Griselda - continúa tratando de cómo reaccionó Petrarca ante los cuentos del Decamerón. Para Petrarca, son historias horrorosas, pestilentes, que ponen en primer plano la miseria humana, pero están bien escritas y decide elegir la última para traducirla en latín. Petrarca ofrece una sola razón: es la que más le gusta. Trasladarla al latín significa llevarla a otro mundo. No ver que para Petrarca todo es un juego literario es un error.

En relación a Valter y Griselda poco cambia, pero el valor moralizante es su elemento más importante a destacar. Es un valor moralizante llevado al extremo, pero encierra una connotación de sumisión incondicional al esposo. Lejos de lo que se puede llegar a pensar, y teniendo en cuenta siempre la canción de Fiammetta y el final de la novela de Boccaccio, no creo que deba considerarse, por lo menos por parte de Boccaccio, una historia que se cuente con intenciones morales. Más bien se cuenta para destacar lo absurdo de la fidelidad conyugal y las exageraciones en el trato a Griselda, está ahí como motivo de divertimento y para captar la atención del oyente, del lector, en definitiva. No obstante esa connotación moralizante es la que lleva a Petrarca a "salvar" esta historia y, como admira la manera de escribir de Boccaccio, le dice que la traduce porque le ha gustado.

Metge, como Petrarca, también tenía una mentalidad abierta y moderna ${ }^{30}$, pero hay en su obra un juego de carácter literario que no debe olvidarse. El juego con-

\footnotetext{
${ }^{30}$ No creemos que Petrarca considerara esta historia simplemente una fábula, un cuento de carácter arbitrario. Petrarca sabía de lo que se trataba y cuando dice que le gusta la historia implica dos cosas: 1) respeto y admiración por el estilo de Boccaccio, conociendo la intención del mismo; y 2) aceptación ideológica y búsqueda de la belleza, lo que quiere decir "recreación literaria". Para la idea mencionada aquí de Petrarca, véase Júlia Butinyà Jiménez, Del "Griselda" català al castellà. Reial Acadèmia de Bones Lletres. Barcelona: 2002, p. 35.
} 
siste en presentar una historia con elementos propios de cierto tipo de literatura religiosa como pueden ser los exempla, que son cuentos. Explica Ysern:

Podríem dir que l'exemplum era una unitat narrativa mínima, amb un sentit predeterminat teòricament, clarament didàctic, i amb un significat fixat només en relació amb el seu context, normalment, un sermó. Com més s'utilitzaven aquests exempla en textos literaris, més exemplaritat perdien, fins a arribar a un moment en què,... el qualificatiu de "literatura exemplar" podia esdevenir una pura etiqueta, de vegades amb clares intencions de vendre garsa per perdiu i disfressar, així, qualsevol possible heterodòxia o "diversió" 31 .

La fidelidad y la connotación que de exemplum puede tener la historia vienen de esa traducción de Petrarca, porque sencillamente en Boccaccio es una historia que se cuenta sin más intención que entretener ${ }^{32}$. En realidad, Boccaccio hace lo que Ysern ha calificado como "vendre garsa per perdiu i disfressar, així, qualsevol possible heterodòxia o 'diversió"'. A Petrarca no le pasó desapercibido y continuó el juego literario con su traducción, aunque originalmente le hubiera movido cierta connotación moral, la de la fidelidad incondicional femenina. No es de extrañar, dado su conocimiento literario, que Petrarca fuera consciente de la necesidad de decir adiós a una connotación meramente moral o religiosa porque, en realidad, lo que le interesaba era la creación literaria. Haciendo referencia a las cartas entre Metge y Petrarca, Butinyà explica:

Nuestra labor va a ser la de afrontar la versión catalana de Metge, quien al enviar su relato traducido lo vuelve a envolver entre dos cartas en clara mímesis petrarquesca; ahora bien, nos fijaremos sobre todo en estas cartas que, a modo de cornisa o marco, determinan la traducción. A nuestro entender, a través de ellas se aprecia la operación por la que Metge devuelve el texto al autor de la historia, Boccaccio, quien situó el relato en el lugar más elevado, cerrando la Jornada de la virtud de la

\footnotetext{
${ }^{31}$ Ysern. Recull..., vol 1, p. 15.

${ }^{32}$ Recio, "Petrarca traductor...", pp. 293-94.
} 
magnificiencia; de este modo, ya no requeriría la sublimación que pretendió Petrarca trasladándolo al terreno de la fe $\mathrm{fe}^{33}$.

Se puede afirmar entonces que Metge hace otro tanto, juega literariamente tal y como señala Butinyà, y es aquí donde el fragmento cobra una gran dimensión: las amplificaciones, los cambios léxicos y todo lo que señala Ysern en su cotejo es una recreación literaria basada en las ideas de la época y en donde destaca la importancia que a su lector le daba Petrarca, poniendo por otra parte de relieve los métodos de traducir en la Corona de Aragón.

La importancia de la traducción de Petrarca y su "sublimación”, no desaparece del mundo de las traducciones del Valter y Griselda. Muy de acuerdo con Butinyà, no deja de sorprendernos que en la traducción castellana de esta historia de 1496 se siga la connotación de la traducción de Petrarca:

Esta hystoria ha sido escripta y recitada desta señora no solamente porque las dueñas que agora son la querrán parescer, y seguir y tener aquella paciencia y constancia que ella siguió y tuuo, que apenas me paresce posible; mas aún por induzir los leyentes y oyentes que mirando y considerando que lo que ella sufrió con gran paciencia por su marido, que assí quería esforçar a suffrir por Nuestro Señor Jesú Xristo, el qual como dize Santiago no tienta a ninguno, empero pruéuanos, y muchas vezes permite que seamos afligidos de muchas persecuciones, no para saber nuestro coraçón, el cual él sabía antes que nos criasse, mas solamente por alumbrar y hazer nos entender según nuestra fragilidad alguna cosa de la bondura de sus altos juicios, assaz cumplidamente he escripto para los constantes varones para ver si hallara alguno que por su Dios quiera suffrir tanto como esta rústica mugercilla por su mortal marido sufrió (fol. cljr) ${ }^{34}$.

\footnotetext{
${ }^{33}$ Butinyà, En los origenes..., p. 56. Las cartas pueden encontrarse en las pp. 48-486. Este libro es básico para los estudios tanto de Metge como del Humanismo. En relación a Boccaccio, consúltese de la misma autora "De Metge a Petrarca pasando por Boccaccio", Epos, 9 (1993), pp. 217-231.

${ }^{34}$ He consultado el ejemplar de la Biblioteca Nacional de Madrid (R/11750).
} 
Tanto Bourland como Cano Ballesta piensan que el modelo de Valter y Griselda, por lo menos en castellano, es Petrarca ${ }^{35}$. Por supuesto que se refieren a la historia que nos ocupa, no a la traducción completa ${ }^{36}$. Resulta muy importante esta afirmación, porque nos demuestra la aceptación de Petrarca en Castilla y la relevancia de su poética entre los intelectuales, lo que queda reflejado en el corpus que ha quedado de los Triunfos e incluso sus tres traducciones ${ }^{37}$. No obstante, y por lo general, la idea de que en Valter y Griselda debe existir una connotación moral o religiosa, la connotación que Butinyà denomina "sublime", queda desplazada y arrinconada. Para Petrarca, es necesario señalarlo una vez más, es un juego literario y lo demuestra cuando traduce la conversación que tienen los criados con Valter, llevando a cabo una magnífica amplificación ${ }^{38}$.

Una posible explicación con respecto a que el traductor castellano en 1496 siguiera en su traducción la línea ideológica que traza Petrarca, además de por la

${ }^{35}$ Caroline Brown Bourland, "Boccaccio and the Decameron in Castilian and Catalan Literature", Revue Hispanique, 12 (1905), p. 164. Juan Cano Ballesta, "Castigos y doctrinas que un sabio daua a sus hijas: un texto del siglo XV sobre educación femenina", Antonio Vilanova, ed., Actas del X Congreso de la Asociación Internacional de Hispanistas, PPU, Barcelona, 1992, p. 144.

${ }^{36}$ Para estas cuestiones, véanse mis trabajos "Petrarca traductor..." y "Del latín al vernáculo: la difusión peninsular del Decamerón”, Livius, 9 (1997), pp. 109-19.

${ }^{37}$ He editado varias de las traducciones de Petrarca en los últimos años en la Península: Antonio de Obregón: Francisco Petrarca, con los seys Triunfos de toscano sacados en castellano con elcomento que sobrellos se hizo. Logroño: Arnao Guillén de Brocar, 1512. eHumanista Monographs, 2012, www.ehumanista.ucsb.edu/projects; Los Triunfos de Petrarca comentados en catalán: una edición de los manuscritos 534 de la Biblioteca Nacional De Paris y del Ateneu de Barcelona, North Carolina University Press, Chapel Hill, 2009; El «Triumpho de Amor» de Petrarca traduzido por Alvar Gómez, PPU, Barcelona, 1998. Está en prensa en este momento la edición de la traducción de Hernando de Hozes: Los Triumphos de Francisco Petrarcha, ahora nuevamente traduzidos en lengua castellana, en la medida, y numero de versos, que tienen en el toscano, y con nueva glosa. Medina del Campo, Guillermo de Millis, 1554, Universidad Gabriela Mistral, Santiago de Chile. He publicado varias trabajos donde se destaca la difusión y la importancia de los Triunfos: "Los Triunfos de Petrarca en los cancioneros: rastros de un género olvidado", Marta Haro Cortés et al., ed., Estudios sobre el Cancionero General (Valencia, 1511): Poesía, manuscrito e imprenta, Universitat de València, Valencia. 2012, vol. 2, pp. 349-369; "Las traducciones del Triunfo de Amor de Petrarca de Alvar Gómez y Guillaume de Belliard: importancia de la poética cancioneril castellana", Revista Chilena de Estudios Medievales, 1 (enero-junio 2012), pp. 55-78; Petrarca y Alvar Gómez: la traducción del «Triunfo de Amor», Peter Lang, Nueva York, 1996; “Algunas notas sobre el concepto de triunfo como género: el caso del Triunfo de Amor de Juan del Encina”, Hispanófila, 109 (septiembre 1993): 1-10.

${ }^{38}$ Recio, "Petrarca traductor...", pp. 295-296. 
gran relevancia que el poeta italiano ya tenía, puede encontrarse en el ambiente imperante de aquella Castilla ${ }^{39}$.

Además, debe destacarse, que en el juego literario de Petrarca, el lector es muy importante y hay que presentarle algo claro y que sea de su agrado:

Delectatus sum ipso in transitu; et si quid lascivie liberioris occurreret, excusabat etas tunc tua dum id scribers, stilus, ydioma, ipsa quoque rerum levitas et eorum qui lecturi talia videbantur (290).

Narrar es un arte y la narración, aunque se trate de una traducción, ha de ser clara y entendible. Petrarca es consciente de ello, y esta misma actitud la encontramos en los traductores de la Corona de Aragón del siglo XIV:

Tornant al segle XIV, quelcom característic de la Corona d'Aragó, impensable en la castellana, és aquesta prioridad donada pels traductors als seus lectors. Els lectors i la idea de la claredat en el trasllat els fan adoptar certes llibertats, responent a una mentalitat oberta en vers la traducció. Es pot dir que aquesta mentalitat respon a una assimilació d'una ideologia nova: l'Humanisme. Cal recordar que estem partint d'un canvi que neix a Europa i que es relaciona amb el tipus de lector, la societat, i l'ús de les llengües. És una visió diferent de l'art i el seu destinatari. ${ }^{40}$

También la actitud de Boccaccio es la misma en lo que a la claridad de una historia se refiere, y para él el lector resulta fundamental ${ }^{41}$. Recordemos lo que

\footnotetext{
${ }^{39} \mathrm{He}$ escrito varios trabajos al respecto, pero pueden consultarse "Vernacular Translations in the Crowns of Castile and Aragon (1352-1515)", Frank A. Domínguez y George D. Greenia, eds., Castilian Writers, 1400-1500, Gale, Nueva York, 2003, pp. 368-379; "Comentarios y lenguas vernáculas: la traducción como vehículo cultural y propagandístico", Revista de Lenguas y Literaturas Catalana, Gallega y Vasca, 9 (2003): 321-332.

${ }^{40}$ Recio, "El lector: factor determinant per als traductors de la Corona d'Aragó", Júlia Butinyà y Antonio Cortijo Ocaña, eds. L'Humanisme a la Corona d'Aragó, Scripta Humanistica, Potomac, 2011, p. 187.

${ }^{41}$ Para el tema del lector en Boccaccio, véase María Hernández Esteban, "El juego de la inserción en el Decamerón. La introducción a la IV Jornada”, Claudio Guillén y Carlos García Gual, eds. El
} 
ya explicó Almansi en relación a las historias que aparecen en la Jornada Diez y al Decamerón en general. Al hablar de la estructura de la Jornada Diez, señaló:

The cornice manages to insert even the most fantastic stories into a recognizable human dimension, so that patina of almost domestic familiarity is allowed to tone down the purest flights of imagination ${ }^{42}$.

Entendemos ahora por qué Ysern hablaba de pérdida de ejemplaridad y de etiquetas. Si además, del factor lector, y la claridad narrativa, vamos al mundo de la traducción, la cuestión de la claridad, al menos en la Corona de Aragón, se hace más visible y determinante. A diferencia de Castilla, la libertad al traducir era algo común entre los traductores de la Corona de Aragón.

Que en la presente traslaçión tove tal manera que non de palabra ha palabra, ne por la orden de palabras que está en el original latino, mas de palabra a palabra segund el entendimiento e por la orden que mejor suena, siquiere paresce, en la vulgar lengua. En tal guisa que alguna cosa non es dexada ho pospuesta, siquiere obmetida, de lo contenido en su original, antes aquí es mejor declarada e será mejor entendido por algunas expresiones que pongo, acullá subintellectas, siquiere impríçitas ho escuro puestas, segund claramente verá el que ambas las lenguas latina e vulgar sopiere e viere el original con esta traslaçión comparado ${ }^{43}$.

relato intercalado, Fundación Juan March-Sociedad Española de Literatura General y Comparada, Madrid, 1992, pp. 29-40.

${ }^{42}$ Almansi, p. 13.

${ }^{43}$ Estas palabras pertenecen al apartado "Avisaciones" del prohemio de la traducción de la Eneida que Enrique de Villena llevó a cabo entre 1427-1428 (Pedro Cátedra, "Introducción”, Enrique de Villena, Obras completas, Turner, Madrid, 1994, vol. 2, p. 29). También puede consultarse Ramón Santiago Lacuesta, La primera versión castellana de "La Eneida" de Virgilio, Biblioteca de la Real Academia Española, Madrid, 1979, p. 43. Para las cuestiones de traducción en Aragón y en Villena, véanse tres trabajos de Recio: “'Por la orden que mejor suena': traducción y Enrique de Villena”, La Corónica, 24.2 (Primavera 1996), pp. 140-513; "Panorama de la traducción vernácula en la Corona de Aragón: su relación con Castilla," Liceus, (2006): 124-137; "El lector: factor determinant per als 
En este artículo sobre Villena traductor señalo las distintas generaciones de traductores en la Corona de Aragón y, aunque hablo de Metge como un admirador de la lengua latina, no es menos cierto que se encuentra dentro de una tradición muy lejos de la tendencia a presentar traducciones oscuras, actitud muy común, por el contrario, en el ambiente intelectual todavía en la Castilla del XV, la misma que había sepultado las ideas de San Jerónimo, recogidas por Alfonso de Madrigal, el Tostado, y escritas hacia $1450^{44}$ en la introducción de su Tostado sobre Eusebio $^{45}$. Metge, ya anteriormente en el siglo XIV, con la libertad que le da su entorno cultural, el del Mediterráneo, lleva a cabo un primer borrador de su traducción, siguiendo la literatura de los ejemplos, la literatura moral, sin llevar a cabo ningún juego retórico ni narrativo ni estilístico, ciñéndose a lo que él consideraba el meollo de la historia, el centro ideológico. Más tarde, muy posiblemente continuando las directrices de la narrativa imperante en su tiempo gracias a Boccaccio, sin dejar de tener en cuenta a Petrarca, rehace su historia, la que vemos editada por Martín de Riquer. Metge era consciente de lo que sucedía en el siglo XIV y que yo he dado en llamar "dos postulados casi sagrados":

Bàsicament hom assisteix a un camvi de mentalitat pel que fa al tractament del llatí i a la visió que se'n tenia així com de les llengües vernacles. Hom creia cap a finals del segle XIV dos postulats quasi sagrats: 1) que les traduccions del llatí al vulgar eren imposibles, donat que les llengües vulgars no tenien vocables paral lels als llatins; 2) que les traduccions havien de seguir de la manera més exacta possible el text base, encara que fins i tot arribessin a no ser comprensibles. Com hom pot observar, en primer lloc existeix un problema lingüístic, i en segon lloc un problema de metodologia, amb unes ramificacions i connotacions contundents, que van des de la idea mateixa de la traducció i del traductor fins el concepte de lector ${ }^{46}$.

traductors de la Corona d'Aragó", Júlia Butinyà y Antonio Cortijo Ocaña, eds. L'Humanisme a la Corona d'Aragó, Scripta Humanistica, Potomac, 2011, pp. 185-203.

${ }^{44}$ Recio, "Alfonso de Madrigal (El Tostado): La traducción como teoría entre lo medieval y lo renacentista”, La Corónica, 19.2 (Spring 1991): pp. 112-131.

${ }^{45}$ Recio, “Alfonso de Madrigal...”, pp. 113-114.

${ }^{46}$ Recio, "El lector: factor determinant...”, p. 186. 
Por lo tanto, este fragmento que presenta Ysern, es de capital importancia porque es una muestra de cómo los escritores humanistas cambiaban, adaptaban y modificaban un relato en función de un público y de una concepción de la narración. Son muy esclarecedoras estas palabras de Ribera Llopis:

Sólo nos cabe añadir, tras esta última y ya advertida licencia lectora, una única cuestión. En sus obras hasta este momento mencionadas hallamos términos como novel·les, recitar, història, raonament... entre algunas que otras voces que remiten al ejercicio de la narración. Claro está que la presencia de esos conceptos en los modos discursivos medievales no los hace privativos de uno solo de estos últimos frente a los otros. Bernat Metge, en cualquier caso, los utiliza con corrección en momentos en que la actuación que se dispone a llevar a cabo es, exactamente, la de narrar, ejecución que resuelve con fluidez y desde la cual, si ese es el caso, puede volver o pasar a un diferente modo de escritura. Narrador no siempre accidental y, en todo caso, conocedor de los recursos de la narración, el uso que de ellos hace Bernat Metge es un arma más que pone por su parte a favor de la consolidación tanto de su verdad como de sus devociones literarias ${ }^{47}$.

Otro ejemplo que muestra la actitud de Metge lo ofrece el final del fragmento. Si se comparan los dos textos, el fragmento y el editado por Martín de Riquer, se ve lo escueto del primero y su diferencia con la edición publicada por Riquer. Aparte de que Metge escapa de cualquier connotación religiosa o "sublime", es indiscutible que también escapa de la festividad excesiva que vemos en el Decamerón. Metge lleva a cabo un final que si comparamos las dos versiones, las del fragmento y la editada por Riquer, el juego literario y el intento de seguir una norma narrativa dentro de una traducción es visible. Veamos primero el fragmento:

Aprés de molts anys, ab gran pau e ab gran concòrdia visqueren. E Galter son sogre, [a] lo qual havie mostat haver menyspreu, mudà en casa sua e l'aach ab gran reverència. E despuys

\footnotetext{
${ }^{47}$ Juan Miguel Ribera Llopis, "Usos y recursos narrativos en el Humanismo románico en ciernes: A propósito de Bernat Metge", eHumanista, 13 (2009), p. 125.
} 
sa ffilla honradament maridà e son ffill lexà succeÿdor en casa sua, alegre de son matrimoni e de sos inffants (301).

En la edición de Martín de Riquer:

Aquí hac tota la gent gran goig e alegria, e en aquell jorn fo feta major festa e pus sollempna celebració que no lo dia de las nossas. E puys per molts anys visqueran abdosos en gran pau e concòrdia. E Valter féu venir a casa sua Janícola, sogra seu fort pobra, al qual ell no havia dat semblant que 1 preàs res per ço que no fos fet empatxament a la experiència que ell volia fer a ssa muller, e féu-li gran honor e molt de bé. Puys col·locà sa filla en magníffich e honest matrimoni, e, aprés sos dies, lexà son fill senyor e successor de la sua terra (152).

El ambiente que Metge recoge en las primeras frases de este final es indiscutiblemente de fiesta, sin canciones, pero con un gran regocijo. Además, hay un deseo explícito de informar al lector y de que no se termine la historia de una manera seca y brusca ${ }^{48}$. Contrasta con lo escueto del fragmento, que nos parece de nuevo ser más bien un borrador, por parte de Metge.

Posiblemente con este fragmento de Valter y Griselda estemos ante una primera traducción y redacción de Metge que serviría, por una parte, para tener ya en mente a Boccaccio y las ideas de Petrarca que sobre la claridad debía tener un relato y, por otra parte, para no olvidar, por supuesto, la concepción de la traducción legible y adaptada a la sociedad y a la cultura a la que se traducía. Se unen así, un proceso de traducción y, por necesidad, de narración, en donde el lector es una pieza fundamental. Al decir una primera traducción y redacción no quiere decirse que el fragmento no sea claro. Lo que significa es que muestra cómo Metge entendió, a través de un proceso de traducción, la necesidad de adoptar la nueva manera de narrar que se alejaba del ejemplo y del sermón. Metge aceptaba, a pesar de su reverencia al latín, la narrativa humanista, la de "un tiempo nuevo", y que en definitiva se alejaba de un mundo que tenía "clares intencions de vendre garsa per perdiu i disfressar, aixi, qualsevol possible heterodòxia o "diversió"”.

\footnotetext{
${ }^{48}$ Para más información detallada y filológica, Ysern, “Sobre el fragment...”, pp. 357-360.
} 